Fecha de recepción: marzo 2011 Fecha de aceptación: junio 2011 Versión final: septiembre 2012

\section{La propiedad intelectual y el diseño de indumentaria de autor}

Sofía Marré *

\begin{abstract}
Resumen: En nuestro país existen más de un centenar de diseñadores de indumentaria que se diferencian con sus productos de aquellos impuestos por las tendencias globales. Estos diseñadores independientes, son pequeños emprendedores que nutren su creatividad y originalidad de la cultura local, diversa y extensa.

Este sector sufre la constante amenaza de la copia: retailers, marcas, diseñadores extranjeros, entre otros, observan sus propuestas ávidos de nuevas inspiraciones demandadas por los consumidores. La copia suele colaborar en la legitimización de los creadores e innovadores. Sin embargo, para estos diseñadores, que cuentan con estructuras de trabajo muy pequeñas y poco capital para invertir en difusión y posicionamiento, la copia puede convertirse en un arma de doble filo capaz de llegar a destruir todos sus sueños.

En esta industria no existe una legislación para proteger las creaciones. El ensayo analiza la copia en la industria de la moda y la necesidad de derechos de propiedad intelectual para las prendas originales de indumentaria.
\end{abstract}

Palabras clave: copia - derechos de propiedad intelectual - diseño de indumentaria - emprendimientos nacionales - gestión del proceso creativo - legislación - marcas.

[Resúmenes en inglés y portugués en la página 57]

(*) Formada en el ámbito de la gestión de organizaciones productivas. En el 2009, cursó el Posgrado internacional en Gestión y Política en Cultura y Comunicación, en la Facultad Latinoamericana de Ciencias Sociales (FLACSO). En el 2006 fue becada por la Universidad de San Andrés, la Universidad Torcuato Di Tella y Cedes, en el posgrado de Management de Organizaciones sin fines de lucro.

En nuestro país el interés por incursionar en el diseño de indumentaria se incrementó fuertemente a partir del año 2001, cuando las condiciones de mercado favorecieron el desarrollo de la industria nacional. Este fenómeno estuvo acompañado de una oferta académica cada vez mayor, logrando instalarse como una carrera de nivel universitario en universidades públicas y privadas. En la actualidad, existen centenares de diseñadores de indumentaria que buscan diferenciarse de las tendencias europeas y americanas a través de la investigación morfológica de las prendas, las texturas y los materiales, volcando su impronta personal en cada creación. En su mayoría, son pequeños emprendedores que buscan consolidarse como referentes del diseño nacional y 
aspiran a convertir su negocio en una marca reconocida.

Las propuestas de estos diseñadores son variadas e interesantes. La creatividad es una ventaja competitiva que se alimenta de la cultura a través del patrimonio tangible e intangible. El proceso, la gestión y el producto creativo son claves a la hora de desarrollar un emprendimiento exitoso. Para este sector en particular, la copia o la falsificación comienza a ser una amenaza desde el momento en que colocan sus productos en el mercado: retailers, marcas, diseñadores extranjeros, entre otros, observan sus propuestas ávidos de nuevas inspiraciones demandadas por los consumidores.

La copia suele colaborar en la legitimación de los creadores e innovadores. Sin embargo, para estos emprendedores que cuentan con estructuras de trabajo muy pequeñas y poco capital para invertir en difusión y posicionamiento, la copia puede convertirse en un arma de doble filo capaz de llegar a destruir todos sus sueños.

Esta investigación analiza la copia en la industria de la moda y la necesidad de tener o no derechos de propiedad intelectual para las prendas originales de indumentaria. La bibliografia referida a esta temática en nuestro país es escasa debido a que se trata de una industria relativamente joven. Tomaremos como referencia textos y casos de países subdesarrollados donde la moda tiene una larga trayectoria en el mercado.

\section{La Cultura como un elemento fundamental de la producción en la industria de la moda}

A diferencia de algunas industrias culturales como el cine y la música, la industria del diseño de indumentaria no cuenta con herramientas lo suficientemente estrictas para proteger sus creaciones de la copia inescrupulosa.

Una marca de ropa puede proteger su marca y su logo, pero en muy pocos casos sus diseños. Como diseñador, uno podría patentar un nuevo tipo de tela, textura, dibujo sobre tela, un cierre innovador, pero la mayoría de los diseños de las prendas no pueden ser patentados. Las prendas carecen de derechos de autor ya que son consideradas como prendas de utilidad, es decir que más allá de lo ornamental tienen como finalidad el vestir. Los diseñadores han sido capaces de elevar el diseño práctico (de utilidad) en un diseño ornamental.

En la actualidad, cualquier persona puede copiar o tomar algún elemento de una prenda actual o de la historia de la moda e incorporarlo a su propio diseño. La creatividad en esta industria en particular es infinita, debido a que no existen restricciones en la copia. Los estilos y diseños originados por los creadores se convierten en bienes de uso público cuando salen al mercado. Cualquier persona que tenga acceso a una prenda puede adquirirla, inspirarse en nuevas creaciones o incluso copiarla. La competencia y la copia aceleran el proceso creativo obligando a los diseñadores a reinventarse continuamente.

La creatividad y la originalidad son las principales fuentes competitivas en la industria de la moda. Estas características intangibles se alimentan necesariamente de la cultura, que juega un rol fundamental contribuyendo de manera significativa en la producción de las prendas creativas. La década del 60, por ejemplo, dejó una impronta de estilo muy particular en la historia de la moda, de la cual diseñadores contemporáneos se nutren reinventándolas y atribuyéndoles su propio estilo y creatividad.

Los creadores de prendas se alimentan, entonces, de la herencia cultural que se da tanto en el 
patrimonio cultural tangible como el intangible. El tangible es determinado por los materiales, modelos, diseños, telas, entre otros. El patrimonio cultural intangible es determinado por la reputación, el conocimiento, la creatividad, los usos, representaciones, expresiones, conocimientos y técnicas.

El caso de la alta costura francesa, nos permite aproximarnos aún más a la comprensión de la moda y el patrimonio cultural intangible. Christian Barrere (2008) plantea que la cultura interviene a través de la creatividad y la herencia. El diseño actual se alimenta de la creatividad del pasado que ha ido acumulándose hasta construir patrimonios que simultáneamente se agregan. Cuando las industrias culturales utilizan de manera simultánea la creatividad y su patrimonio cultural se ven beneficiados de un círculo virtuoso en el que los bienes, el conocimiento y las ideas producidas constituyen herencias que favorecen a la creatividad.

$\mathrm{Al}$ momento de crear, un diseñador puede utilizar los aprendizajes de culturas pasadas y volcar su propia innovación. La creatividad y la herencia se manifiestan en el producto creativo, en la gestión creativa y en la institución creativa. Este fenómeno se da principalmente en la alta costura y luego se despliega en el pret à porter y en la moda masiva.

En una industria estándar existe una tendencia a mejorar la tecnología por lo que es probable que cada producto sea substituido por uno mejor, de mayor sofisticación o más económico. Cada tecnología es substituida por una más eficiente. En consecuencia, el valor de las viejas tecnologías y los bienes desactualizados desaparecen rápidamente.

En el caso de la industria de la moda, puede existir innovación y avances tecnológicos, pero no es esta la característica la que enaltece el producto. Al contrario, la moda como industria, se caracteriza porque los consumidores pueden preferir la moda de los años setenta a la de los sesenta, mientras que nadie está demasiado interesado en cual fue la tecnología utilizada para llegar a elaborar el producto.

El diseñador utiliza una gran cantidad de aportes e inspiraciones: la coyuntura, las películas exitosas, las tendencias en otras disciplinas como la arquitectura o el diseño, las personalidades del mundo del espectáculo, la calle, etc. Independientemente del largo de una falda o del color dominante de la temporada, cada diseñador crea su propia colección con un estilo, en relación a su propia herencia cultural.

La creatividad no sólo se refiere al aspecto artístico sino también a la gestión del proceso productivo. La gestión empresarial juega un rol clave para lograr la sustentabilidad del negocio a largo plazo. Las crisis y las condiciones económicas obligan a los gerentes a estar en constante cambio y adaptación. Existen infinidad de casos de diseñadores que con mucho esfuerzo han iniciado un negocio que, después de un tiempo, han tenido que cerrar. Los sobrevivientes han sido aquellos que han optado por un estilo nuevo y creativo de gestión empresarial.

Hasta los años 50, las casas de la alta costura francesas fueron capaces de unir la creatividad con el conocimiento artesanal de manera provechosa y rentable. Este saber fue transmitido de generación en generación de trabajadores que tenían las habilidades técnicas para elaborar prendas muy sofisticadas. Sin embargo, las condiciones económicas cambiaron significativamente cuando el modelo elitista dio lugar al modelo de mercado. Fueron muchas las casas de alta costura que desaparecieron. Luego de la Segunda Guerra Mundial, quedaron unas 106 casas de alta costura en París, en 1967, 19 y en la actualidad sólo quedan unas 10. Desde los años 70, la gestión empresarial ha sido decisiva para estas casas. Además de un diseñador y un director artístico, son manejadas por un gerente que ha logrado desarrollar nuevas estrategias dada las 
condiciones y constantes cambios en el mercado.

En cuanto a lo que a la creatividad institucional respecta, cuando ésta se encuentra presente por mucho tiempo, como en el caso de la alta costura francesa, las políticas públicas emergen para mejorar el arte, la moda, la creatividad y las asociaciones comerciales.

La reproducción de los productos con diseño ha dado lugar a la construcción de un patrimonio de gustos. La existencia de una herencia de gustos y preferencias comunes resulta en prendas más homogéneas. En el mercado esto permite que la demanda se ajuste a la oferta, haciendo más entendible a la moda y más creíble, legitima el trabajo creativo como una creación de moda y construye una ventaja competitiva en el mercado mundial. Todos los bienes de lujo de la industria francesa se ven beneficiados por esta imagen que se ha logrado construir a lo largo de muchos años. Los consumidores demandan moda francesa y productos de lujo dando por sentado que tendrán su especial toque francés. La herencia cultural, en particular la intangible, influencia al individuo y sus preferencias sociales, consecuentemente esto afecta a la demanda en la medida que los productores puedan generar demanda de estos bienes a través de las estrategias de comunicación.

¿La creatividad, entonces, debe ser protegida? Por un lado tiene un valor directo, como por ejemplo el caso del éxito de la marca Dior que resulta del talento de Galliano. Y por otro lado, es un valor indirecto que ha ido acumulándose en el patrimonio dando una gran cantidad de efectos sobre la moda y el lujo. Por ello, los productores de moda deben buscar un rol creativo en la organización de un sistema de derechos de propiedad intelectual que sirva de influencia para definir la gestión de estos derechos.

En su libro El Imperio de lo efímero, el filósofo francés Giles Lipovetsky (1987) explica que la moda

...no puede ser identificada con la simple manifestación de las pasiones vanidosas o distintivas, sino que se convierte en una institución excepcional, altamente problemática, una realidad socio histórica característica de Occidente y de la propia modernidad... es uno de los espejos donde se ve lo que constituye nuestro destino histórico más singular: la negación del poder inmemorial del pasado tradicional, la fiebre moderna de las novedades, la celebración del presente social.

\section{Las virtudes de la copia en la industria de la moda}

De acuerdo a la Organización de la Cooperación y Seguridad Europea, las falsificaciones están inundando las calles de Europa con consecuencias muy preocupantes para la industria textil europea. Las falsificaciones representan un $9 \%$ del total del comercio mundial que equivale a U\$S 450 billones. Una porción considerable de esta cifra corresponde a moda: $20 \%$ a textiles e indumentaria, $5 \%$ a relojes y un $10 \%$ a perfumes y cosméticos. Las estadísticas sugieren que solo el 3\% del tráfico de las falsificaciones es detenido en las aduanas.

En Brasil, de acuerdo a una encuesta realizada en Julio de 2003 por la Comisión Europea, la industria de la indumentaria pierde $€ 1.5$ millones por año como consecuencia de la copia.

Las marcas de ropa que han construido gran valor y reputación invierten sistemáticamente enormes sumas de dinero en promocionar sus productos. Este tipo de empresas en particular, sufren de manera frecuente el plagio o la copia. Los juicios que han sido ganados por estas 
empresas no son muchos, e insume mucho tiempo y dinero lograr que los falsificadores recompensen las pérdidas causadas por la venta indiscriminada de productos copia de los originales. Entre algunos ejemplos de juicios millonarios ganados por las marcas, se encuentra el de Tommy Hilfiger, que en el 2003 ganó U\$D 11 millones de dólares en un juicio que le hizo a la Empresa Godody's family Clothing por copiar sus remeras.

En el 2008 Adidas le gana un juicio al retailer americano de zapatos Payless Shoes. Payless habría vendido zapatillas con las clásicas rayas de Adidas. Un jurado de Oregon, obligó a pagar al retailer U\$D 305 millones. Este caso fue record de infracción a una marca.

En 2004, la marca Cartier llevaba iniciados 2,500 procedimientos legales que le insumían $\$ 3.8 \mathrm{~m}$ anuales; Louis Vuitton iniciaba más de 1,000 casos por año así como también Burberry, esta última marca siendo muy agresiva en sus esfuerzos por proteger la exclusividad de sus creaciones. La teoría estándar de derechos de propiedad intelectual sostiene que la copia destruye el incentivo para innovar. Sin embargo, en la industria de la moda, las marcas continúan innovando a una gran velocidad. Las grandes empresas de ropa invierten importantes sumas para proteger el valor de sus marcas, pero en su mayoría parecen aceptar la apropiación de sus diseños como un hecho común. Muchas empresas manifiestan públicamente los perjuicios económicos que ocasiona la copia, sin embargo, también suelen ver con agrado la publicidad gratuita que esa copia les genera. A pesar de la falta de protección legal, en Estados Unidos por ejemplo, la industria de la moda es la que más ha innovado respecto al resto de las industrias culturales. Las estadísticas demuestran que las industrias que tienen pocos derechos de propiedad industrial como la moda, el mobiliario, los alimentos y los autos y que están obligadas a innovar continuamente son las que más facturan versus otras con mucho mayores protecciones como la industria de la música y el cine. Los autores Raustiala \& Sprigman plantean en su libro La paradoja de la piratería (2006), que la falta de protección intelectual en la industria de la moda no es especialmente dañina para el sector, sino que por el contrario, promueve la innovación y beneficia a los diseñadores. Esto no quiere decir que la copia no pueda causar daño a algún diseñador en particular. Sucede que los diseñadores que se han visto perjudicados por la copia no están fuertemente incentivados para aplicar derechos de propiedad intelectual ya que ellos también han copiado en algún momento. Las ideas originales son pocas y la existencia de las tendencias de moda típicamente demuestra que existen muchos actores que copian o reutilizan ideas. Hoy en día los diseñadores encuentran inspiración en cómo se viste la gente en la calle, donde las combinaciones las establece el propio consumidor.

Para justificar dichas afirmaciones, los autores aportan dos teorías: la teoría de la obsolescencia inducida y el anclaje de las tendencias. La primera sostiene que si la copia fuera ilegal, el ciclo de la creatividad ocurriría de manera muy lenta. La falta de protección de los diseños creativos y el régimen de libre apropiación a través de la copia, aceleran la propagación y difusión induciendo al estado obsoleto de los diseños.

A modo de ejemplo, una cartera de Gucci o Prada tiene valor, en parte, porque la gente que está a la moda la posee. A medida que los estilos se propagan a más y más clientes, con frecuencia el prestigio, obtenido a través de dicho producto, disminuye para aquellas personas que primero lo adoptaron.

El proceso suele ser siempre el mismo, la distinción de las propuestas de moda que en etapas tempranas aseguran una buena distribución de los productos en el mercado, es luego destruida a medida que su uso es propagado. 
A medida que un diseño es copiado con costos más económicos, se convierte en un bien más accesible, y por lo tanto, se propaga más rápidamente. Existe un punto de inflexión en que la propagación del diseño erosiona el valor del posicionamiento del producto. Esta situación lleva a aquellos perseguidores de un status a buscar otros productos que lo diferencien de las masas. Por consecuencia, los primeros adoptadores de un status se corren a una nueva moda, que luego será copiada y propagada y así comenzará nuevamente el ciclo.

Prada dijo "Dejamos que nos copien. Y cuando lo hacen, lo dejamos de hacer" (2006). Las grandes marcas responden a la obsolescencia con nuevos diseños dando giros más rápidos. La libre apropiación de las creaciones de los diseñadores contribuyen a que los mismos se vuelvan obsoletos de la siguientes dos maneras: en primer lugar, la copia con frecuencia resulta en un marketing de calidad menor, además esta apuntado a consumidores que de otra manera no podrían consumir diseño. Lo que era de elite rápidamente se convierte en masivo.

En segundo lugar, muchos de los artículos copiados no son reproducidos con todos los detalles, al contrario por lo general los falsificadores se apropian de la idea y luego la rediseñan con sus propios ajustes. Esto a su vez, acelera aún más el proceso por el cual el diseño (y los derivados) se convierten en menos atractivos para los primeros que lo adoptaron.

Si la industria de la moda se beneficia por mantener un ciclo de obsolescencia inducida, al desarrollar muchos estilos cada temporada, entonces debería asegurar que los consumidores entiendan en que momento los estilos han cambiado. En resumen, para existir, "las tendencias deben ser comunicadas como también creadas". (Raustiala y Sprigman, 2006, p. 1728). Para anclar las tendencias estas deben ser bien definibles. Es decir, cuando la industria produce una gran variedad de diseños, sólo las tendencias discernibles se distinguen.

Por su parte, la infinidad de estilos y propuestas ha permitido también la democratización de la moda. Giles Lipovetsky, (1987) filósofo francés especializado en esta temática argumenta:

Bajo la égida de la Alta Costura, se impusieron una misma estética de la gracia, un mismo imperativo de delicadeza, de lo apropiado, de lo elegante y una misma búsqueda de la gran clase y del encanto femenino. La ambición común era encarnar de modo supremo la elegancia del lujo, el chic refinado, y otorgar valor a una feminidad afectada e ideal. A lo largo de los años sesenta y setenta, ese consenso estético fue pulverizado por el desarrollo del sportwear, de las modas jóvenes marginales y de los creadores del pret a porter: la homogeneidad de la moda centenaria ha dado lugar a un "patchwork" de estilos dispares.

A diferencia de otras épocas, donde los consumidores seguían estrictamente las tendencias globales, hoy en día existe una necesidad cada vez mayor de comunicar una individualidad a través de un estilo propio. Tanto hombres como mujeres se atreven a recombinar prendas, conformando estilos personales con propuestas más que interesantes. Lipovetsky (1987) explica cómo la moda homogénea de principios de siglo cambió hacia la heterogeneidad de estilos. Para el autor, la moda y la creatividad están directamente relacionadas con la maduración de una sociedad. "La ropa de moda es cada vez menos un medio de distanciamiento social y cada vez más un instrumento de distinción individual y estética, un instrumento de seducción, de juventud y de modernidad emblemática" (Lipovetsky, 1987). 


\section{Tipos de copia}

¿Cómo diferenciar una prenda original de una prenda falsificada? ¿Qué valores son necesarios para enaltecer un producto y diferenciarlo de la copia? ¿Cómo hacer frente a las falsificaciones? ¿Cómo determinar el verdadero creador de una prenda?

Las nuevas tecnologías dificultan cada vez más la diferenciación entre un producto original y su versión falsificada. Sin embargo, para algunos autores, la industria de la moda descansa en la credulidad (Milton, Choi, y Chen, 2004). En el caso de la alta costura, gran parte del valor para el comprador recae en la creencia de que está adquiriendo algo nuevo y exclusivo. Los diseñadores consagrados limitan el impacto de la copia y la piratería cambiando sus diseños cada temporada y limitando la producción y distribución de sus productos. Esta estrategia, exige a los diseñadores a estar continuamente reinventándose, lo cual los posiciona de diferente manera respecto al resto. Los costos de dicha estrategia son muy elevados, pero es sostenido gracias a un grupo muy reducido de compradores con alto valor adquisitivo.

En el caso de la alta costura, quien adquiere la prenda y quien la diseña es lo que le proporciona al producto credibilidad. En la industria de la moda, el indicador de calidad suele ser establecido por las figuras de moda como las estrellas de cine u otras celebridades. Ellos les demuestran a sus admiradores cual es la moda a través de las prendas de diseño que visten. Sin embargo, cuando están inseguros de cómo vestirse con buen gusto, recurren a algunos pocos diseñadores de alta referencia. Dichos diseñadores son los que en definitiva determinan la moda.

Esta industria en particular, se guía por la reputación del diseñador frente a sus colegas, los críticos y el mundo relacionado con la moda. La percepción pública de qué es la calidad es formada, muchas veces, por estos vendedores y constructores de imagen. A modo de ejemplo, la marca Chanel experimentó un incremento explosivo en sus ventas cuando el diseñador Karl Lagerfeld se convirtió en el diseñador de la marca, alcanzando los $\$ 400$ millones de facturación una década después de haberse integrado a la empresa. Al cambiar de diseñador, Chanel demostró cómo la marca, que estaba convirtiéndose en algo estático y aburrido, pudo reinventarse y atraer una nueva generación de clientes.

Existen en el mundo diversos y variados tipos de copia: de productos de bajo valor percibido, de sobreproducción, de copias hechas por marcas, diseñadores o retailers, y en donde focalizaremos nuestra preocupación, de copias realizadas por grandes marcas o retailers a pequeños diseñadores independientes.

Los productos de bajo valor percibido suelen ser una amenaza para los diseñadores o marcas de renombre. La gran cantidad de imitaciones de pobre calidad pueden dañar a largo plazo a la marca, dado que se dificulta desasociar el producto genuino de las copias masivas baratas hechas para que parezcan como el verdadero producto.

Como consecuencia de ello, surgen dilemas éticos. Los diseñadores sostienen que los creadores del trabajo deberían recibir una compensación apropiada por sus esfuerzos creativos mientras que los falsificadores privan a los diseñadores de beneficiarse de su trabajo causándole a largo plazo un daño a la sociedad. Los falsificadores, por su parte, sostienen que, dado que muchas marcas operan en países subdesarrollados, algunos consideran que es un derecho humano básico hacer de su vida lo que sea para sobrevivir. Se jactan simplemente de servir a un mercado de consumidores que de otra forma no podría acceder a una prenda legítima. En dichas circunstancias, se podría argumentar que el bienestar de la sociedad como un todo podría verse 
acrecentado por restricciones más relajadas y que los falsificadores realizan un servicio social. La sobreproducción de productos es la copia menos ofensiva ya que si bien la imitación es de alta calidad y goza de los mismos atributos que el original, su origen es sospechoso. El mismo pudo haber sido confeccionado con las especificaciones originales por el legítimo productor, que para hacerse de una ganancia adicional, generó una partida extra de prendas con el mismo material costoso provisto por la marca. Dicho producto es igual al original, sólo que no posee la autorización del diseñador. Los productos pueden venderse con facilidad en el mercado local, especialmente cuando existe un gran caudal de turismo nacional e internacional. Con frecuencia, las ventas locales de estos productores suelen competir con los artículos originales.

Crear nuevas tendencias es un medio en sí mismo utilizado por los propios diseñadores para proteger su reputación. Al estar continuamente creando nuevos diseños, los diseñadores realmente creativos siempre estarán por encima de los individuos menos capaces. Al encontrarse con propuestas creativas permanentes de alta calidad, los falsificadores no pueden aspirar más que a ser simples copiadores. En la industria de la moda esto es entendido y en algunos casos hasta condenado por el propio sector. Por lo general, las ideas son capturadas por los falsificadores en los desfiles, luego estos le solicitan a sus propios productores a que produzcan copias simplificadas de las versiones de aquellos diseños que ven y les agrada para reproducirlos en grandes volúmenes. Algunos productores directamente fabrican copias económicas de las fotografías de desfiles de alta costura que son publicadas en las revistas de moda.

Se simplifican los diseños actuales para hacer productos al alcance en grandes volúmenes y a precios más bajos. Este tipo de copia suele ser aceptada por la industria no sólo porque las marcas de ropa se ven beneficiadas por la publicidad, sino porque también la copia legitima los diseños. Se podría argumentar que los falsificadores deberían tener una compensación por aportar publicidad valiosa a las marcas.

Las marcas en la industria de la moda se enfrentan a la paradoja de cómo obtener ganancias de la exclusividad. Los productos de lujo tienen características económicas diferentes a otros sectores, donde existe una elasticidad en los precios bajos sobre la demanda. A diferencia de otras industrias donde el incremento de precios reduce la demanda, en esta industria los precios altos, en algunos casos, pueden generar mayor demanda dado que la escasez juega un rol principal en determinar un valor y una imagen.

Esta estrategia significa tener que limitar la producción. Sin embargo existe el riesgo de que el volumen de ventas de la marca sea insuficiente para recuperar los costos de producción. Las marcas, entonces, se ven tentadas a incrementar su producción por fuera de la idea de posicionarse como una marca percibida por su exclusividad. El problema es que el incremento de la producción puede impactar de manera negativa en la exclusividad del producto. Para contrarrestar esta situación, existen algunas marcas originales de diseño que se "auto copian", lanzando al mercado segundas marcas de pret a porter a precios más accesibles. Los diseños elaborados en las 1ra marcas tienen su resonancia en las 2das, pero son de una calidad inferior de materiales. Armani es un buen ejemplo para comprender este tipo de estrategia, ya que tiene 6 marcas desarrolladas en el mercado: Giorgio Armani, Armani, Emporio Armani, Armani Exchange, Armani Jeans y Armani Collezioni. En efecto, las grandes marcas de moda utilizan a la alta costura como una herramienta de marketing para alcanzar las ganancias que se generan principalmente por la venta de ropa casual. 


\section{El diseño independiente y la copia}

Por último, el grupo más vulnerable frente a la copia está compuesto por los diseñadores independientes. Se trata de diseñadores de indumentaria que buscan diferenciarse de las tendencias globales. En nuestro país existen centenares de estos pequeños productores que se nutren de sus propias vivencias posicionando su estilo como imágenes de marca. Sus inspiraciones son variables: investigan materiales autóctonos, nuevas texturas, ensamblado de materiales y formas. Los diseñadores tienen "Una fuerte vocación por la diferenciación, que impulsa a las personalizaciones y a juegos de creatividad que unen con la libertad, lo artesanal con lo industrial, lo tradicional con lo alternativo" (Saulquin, 2007).

Los retailers y las grandes marcas de moda, comienzan a tenerlos en cuenta como fuente de inspiración. A diferencia de las grandes marcas, estos diseñadores no cuentan con la estructura necesaria para hacer frente a las imitaciones. Por el contrario, la mayoría son emprendedores que no han logrado darse a conocer lo suficiente para que la gente los reconozca por sus diseños.

La producción y comercialización de estos bienes diferenciales genera no sólo el desarrollo económico sino que también garantiza la diversidad cultural de una comunidad. La primera medición nacional de este fenómeno relativamente nuevo en nuestro país fue realizada a principios de este año por la Fundación Pro Tejer y el INTI (Marino, 2010).

Ambas entidades estimaron el tamaño del sector encuestando diseñadores con más de un año en el mercado y con productos con lenguajes creativos innovadores sostenidos en el tiempo.

Los resultados de la investigación dieron que el sector factura aproximadamente unos $\$ 250.000 .000$ (pesos argentinos). Emplea de manera directa e indirecta unas 3.250 personas siendo sólo el $23 \%$ de los trabajadores empleados directos de las firmas, el resto -77\%- ocupados a través del proceso de tercerización de la producción.

En base a su facturación anual, el universo de emprendimientos puede ser caracterizado como mayoritariamente $(80 \%)$ de micro empresas, con facturaciones inferiores a $\$ 1.800 .000$. El restante $20 \%$ corresponde a pequeñas empresas.

Las empresas complementan la producción de prendas con otros rubros como calzado, marroquinería, accesorios y objetos, logrando ampliar las familias de productos. Esta estrategia permite no sólo ampliar la oferta de bienes para el propio público sino que permite captar consumidores potenciales no habituados al consumo de indumentaria de autor. Si consideramos estos rubros dentro de la facturación anual total podríamos aproximarnos a $\$ 450.000 .000$ (pesos argentinos), un número más que interesante para este sector que se ha desarrollado con gran impulso hace apenas unos 10 años.

Sólo un 27 \% de este universo constituyen micro empresas y PYMES exportadoras. El destino de los productos son diversos: América Latina, Europa y Asia, son los principales receptores.

Dicho informe reveló que existe una base total de 150 diseñadores con distintos niveles de desarrollo distribuidos geográficamente en la Ciudad de Buenos Aires, Provincia de Buenos Aires, Santa Fe, Córdoba, Entre Ríos, Corrientes, Chaco, Misiones, Mendoza, San Juan, Tucumán, Salta, Jujuy, Santiago del Estero, y San Luis.

En nuestro país, la fuerte corriente inmigratoria de principios de siglo 20 ha contribuido a construir una nación con una diversidad de identidades. La globalización durante la década del '90 y la tecnología han permitido mejorar las comunicaciones y acortar las distancias. Nuestros di- 
señadores independientes reflejan la diversidad de su herencia cultural, y esto no es una casualidad. Por ello, ¿si la creatividad es nuestra mejor ventaja competitiva, cómo se la puede proteger?

\section{Instrumentos de Propiedad Intelectual}

La Organización Mundial de la Propiedad Intelectual, OMPI, sostiene que los derechos de propiedad intelectual reducen el riesgo, generan asociaciones comerciales y promueven la competitividad en todo tipo de negocios en la industria de la moda.

Entre las herramientas de propiedad intelectual, la protección de diseños industriales es la más conveniente para la industria dela moda. La registración del diseño ayuda al creador a prevenir que otros exploten su creación ornamental o su aspecto estético, referida a un modelo tridimensional como puede ser un sombrero o un diseño bidimensional como una textura con un estampado. Los argumentos para registrar un nuevo diseño deben evaluarse caso por caso. Registrar los diseños debería ayudar a detener la copia y a luchar contra los competidores inescrupulosos a que continúen copiando.

En la industria de la moda hay tendencias que aparecen y desaparecen con gran rapidez, aunque algunas nunca desaparecen del todo. Muchas prendas se convierten en clásicos. El traje de la marca Chanel, diseñado por Coco Chanel en 1930, todavía hoy se vende y a un precio de U\$S 5.000 cada uno. Muchas marcas de moda se esfuerzan en crear piezas clásicas de diseño, si son exitosas y no han obtenido los derechos de propiedad intelectual adecuados a tiempo, los imitadores podrán copiar su creación. Para los artículos de moda de larga vida, es necesario registrar el diseño industrial para prevenir que otros lo copien.

En Argentina la propiedad intelectual se divide en dos categorías: la propiedad industrial, que incluye las invenciones, patentes, marcas, dibujos y modelos industriales e indicaciones geográficas de origen; y el derecho de autor, que abarca las obras literarias y artísticas, tales como las novelas, los poemas, las obras de teatro, las películas, las obras musicales, las obras de arte, los dibujos, pinturas, fotografías, esculturas y los diseños arquitectónicos.

En Argentina rige la Ley de Protección de los Modelos y Diseños Industriales (N 16.478), que regula las solicitudes y registros de propiedad intelectual. El organismo encargado de dejar constancia de las innovaciones es el INPI (Instituto Nacional de Propiedad Intelectual), cuya misión es registrar y renovar patentes, marcas, modelos y diseños industriales, así como de celebrar convenios de transferencia de tecnología.

En términos técnicos, existe una distinción entre modelos (tridimensionales) o diseños (bidimensionales) industriales, y modelos de utilidad. Los primeros se refieren a la forma o el aspecto estético y ornamental, y los segundos a las funcionalidades del producto (cuando una nueva forma implica una nueva función). Ambas categorías son registrables, aunque requieren trámites diferentes.

Para la industria de la moda, la categoría adecuada es la de los modelos o diseños. El trámite para su registro es sencillo. La dirección de Modelos y Diseños Industriales se limita a verificar los requisitos formales, y si no existen versiones similares o idénticas que se hubieran registrado con anterioridad. Esto corre por cuenta de la persona o empresa que solicita el registro, accediendo en forma gratuita a la base de datos del organismo.

Conseguir un título de Propiedad Industrial no es costoso. La protección concedida tendrá 
una duración de cinco años, a partir de la fecha del depósito y podrá ser prolongada por dos períodos consecutivos de la misma duración a solicitud de su titular. A pesar de las facilidades que existen para tramitar el derecho de propiedad intelectual, en la base del INPI hay solo 6.761 artículos registrados en la categoría: Artículos de vestir y mercería, de los cuales la gran mayoría son zapatos y lencería.

Una de las razones frecuentes para no registrar los diseños de moda es que los productos tienen un ciclo de vida muy corto (por lo general la temporada no exceden de los 6 a 12 meses) para justificarle un tiempo considerable y costo financiero involucrado.

Para los diseñadores de autor, esta herramienta pareciera no resultar útil, ya que obtener una propiedad intelectual no garantiza que el producto no sea copiado. Para ejercer esa herramienta es preciso costear técnicos y abogados que lleven a la justicia el caso.

Según Lucila Negri, una de las pocas diseñadoras independientes que ha registrado prendas en el INPI, registrar un diseño es complicado porque se necesita completar de manera detallada y precisa un formulario que requiere de un conocimiento técnico adecuado. Por lo cual, dicho proceso comienza a ser costoso desde el momento en que se contrata una persona para completarlo. Lucila Negri estudió bellas artes y considera que esta profesión le permite tener una mirada más amplia sobre el diseño de indumentaria. Esta artista plástica devenida en diseñadora tiene un local de indumentaria en Palermo y además vende en locales multimarca.

Lucila adquirió un título de propiedad intelectual en el año 2003 por una prenda de diseño que le llevó un largo proceso de investigación y que considera es el eje de su marca, repitiéndose en cada colección. "Se trata de una falda polifuncional, multitalle con apliques de diferentes telas. Por su carácter de polifuncional, puede utilizarse de varias maneras: como falda y como vestido. El diseño es sustentable porque no tiene derroche de tela."

La prenda tiene un proceso de investigación complejo, es una bajada más simple de lo que fue el vestuario que preparó para una obra de teatro. Dice "Realizar ese vestuario me llevó varios meses: tuve que estudiar la obra, entender los personajes, la época, etc...Esta prenda es ícono de mi marca."

Antes de salir a vender esta prenda, decidió registrarla en el INPI. "Cuando estudié Bellas Artes en la facultad nos insistían mucho en registrar las obras”. Dada las características de la prenda, solicitó un título de propiedad industrial con carácter de modelo de utilidad. Para adquirir este titulo la diseñadora tuvo que justificar el proceso creativo de la prenda.

A pesar de obtener el título, Lucila tuvo dos experiencias de plagio: la primera experiencia fue con un puesto a la calle en el barrio de Palermo, donde encontró un perchero entero con sus faldas confeccionadas en una calidad inferior a las suyas. Se trataba del mismo molde con apliques diferentes. Después de insistir reiteradas veces a la dueña del puesto que retirara las faldas, Lucila tuvo que acudir a un abogado para comenzar un largo camino de querellas y cartas documento que hasta el día de hoy sigue sin resolverse.

La segunda experiencia, fue en el año 2007 cuando envió a coser su colección de invierno a un taller de confección. Unas semanas más tarde, antes de sacar el pantalón a la venta, vio el mismo pantalón que ella misma había diseñado en la vidriera de una conocida marca de ropa. Al investigar, resultó que el propio taller de confección también trabajaba para la marca y había contribuido con el plagio de la moldería y el diseño. "Yo no tengo problema que la gente se inspire en mi trabajo, solo pido que resignifique mis creaciones, que no lucre con mi trabajo" dice Lucila y agrega "se perdió todo el potencial de venta que tenía mi pantalón". 


\section{Cómo lograr cambiar el comportamiento de los imitadores.}

La importancia de tener pequeñas empresas creativas en el mercado se basa en que las mismas aportan fuertemente a la diversidad cultural. "Se reconoce que las pequeñas empresas, sobre todo, facilitan el acceso de muchos grupos -en especial los culturales, étnicos y regionalesque de otra manera no tienen fácil entrada a los medios de las industrias culturales." Yúdice, G. (2005). Dentro de los mercados creativos, la industria textil es particularmente seductora, porque facilita la rápida inserción de nuevos emprendedores. Estos requieren de poco capital económico para comenzar a producir: es posible insertarse en el rubro de la confección con sólo adquirir una máquina de coser.

Con el crecimiento y consolidación de grandes retailers y marcas, que poseen ventajas de costo y recursos, las micro y PYMES creativas enfrentan mayores obstáculos para crecer y progresar. Debido a la importancia que ha tomado el diseño independiente en nuestro país, es momento de comenzar a elaborar políticas de corto, mediano y largo plazo que garanticen la sustentabilidad y la creación de nuevos emprendimientos. En este sentido, el Estado juega un rol fundamental. El desafío es desarrollar políticas públicas y formular una ley de propiedad intelectual a la medida de las posibilidades de los pequeños emprendedores.

En términos de políticas públicas, será imprescindible comenzar por la sistematización de diagnósticos y mediciones del sector, para poder tomar decisiones adecuadas a la realidad del segmento. Ello servirá de puntapié para pensar y crear líneas de financiamiento acorde a las características productivas de este tipo de emprendimientos, y desarrollar herramientas de capacitación vinculadas a la gestión, comercialización y calidad. Asimismo, también será necesario contribuir con el posicionamiento y promoción del sector tanto a nivel nacional como internacional. Para tal fin, será clave aunar esfuerzos entre los diversos sectores del Estado: finanzas, hacienda, comercio, turismo, comunicaciones, educación y cultura. Así como también será necesario fortalecer la transversalidad institucional mediante alianzas entre el Estado, las empresas, el tercer sector, y organismos de cooperación internacional.

El diseño independiente es vulnerable, principalmente, a la copia indiscriminada ejercida por los grandes retailers o marcas. Debiera, entonces, formularse una ley de propiedad intelectual para la industria, enfocada en limitar posibles prácticas predatorias por parte de estos competidores. La ley de propiedad intelectual deberá contemplar la escala productiva y posibilidades de desarrollo de los emprendedores. Para ello, será clave conformar un equipo interdisciplinario de profesionales relacionados al universo en cuestión, que desarrolle un modelo de propiedad que favorezca a la innovación.

La protección legal para los diseñadores independientes debería ser establecida por un período determinado y no de manera indefinida. El paraguas de la protección por un tiempo determinado incentivará al diseñador a establecerse y desarrollar su marca en el mercado.

Las creaciones argentinas deberán ser protegidas no solo a nivel local, sino también a nivel mundial formulando una herramienta que garantice la real autoría de la prenda. Para ello, se deberá conformar un equipo técnico que pueda certificar las nuevas creaciones. Así como plantea Néstor García Canclini (2002) "Si hacemos leyes sólo dentro de cada país no tendrán sustentabilidad. Es indispensable el trabajo de los organismos internacionales para efectuar es- 
tudios regionales, sensibilizar a los responsables de cada país y llegar a acuerdos practicables...". En este sentido, las nuevas tecnologías pueden colaborar con este desafío.

Por su parte, el proceso de inscripción y solicitud de derechos de autor sobre las prendas creativas debería ser ágil, fácil, rápido y económico. El diseñador independiente deberá saber justificar el proceso creativo de sus prendas para hacer frente a los imitadores.

Así como la carrera de Bellas Artes en nuestro país promueve a los alumnos a proteger sus creaciones, los institutos y universidades que dicten la carrera de diseño de indumentaria deberían inculcar y generar conciencia sobre la nueva ley y sus alcances.

A pesar de la falta de protección legal adecuada, y de la ausencia de un plan integral de políticas públicas, los emprendedores poseen algunas estrategias para hacer frente a los imitadores. Ellas consisten en la consolidación de la marca, el fortalecimiento de la reputación y la credibilidad y el foco en la creatividad y la reinvención continua.

La marca como signo con capacidad distintiva, permitirá al consumidor diferenciar un producto o un servicio de otro, jugando un papel clave en el terreno de la competencia. La calidad de los productos o servicios serán conocidos por el público a través de su identificación directa con la marca que los designa. De allí que en muchos casos, el valor inmaterial de la marca sea mayor que el que representan otros bienes que pueda poseer la empresa.

También es necesario ahondar en lo que entendemos como reputación y credibilidad del diseñador como uno de los caminos que aportan tanto fuerza como coherencia a la propuesta de una firma. En este sentido, la construcción de un estilo bien definible para destacarse de las tendencias es otra de las estrategias viables, así como también explorar todos los canales de difusión que actualmente se encuentran disponibles para comunicar la marca, el estilo y la reputación. La creatividad y la constante innovación deberán ser las características sobresalientes de los diseñadores. El ejercicio de reinventarse continuamente será su principal ventaja competitiva. Como resultado de ello, el valor percibido por el consumidor no sólo será el de la prenda adquirida sino también el de la imagen y el concepto desarrollado.

El diseño independiente ha demostrado ser un sector prometedor en cuanto a su crecimiento e impacto en la economía Argentina considerando que tiene sólo 10 años de inserción en el mercado. En este sentido, encuadrar este fenómeno como Industria Cultural pareciera ser lo más adecuado. George Yúdice (2002) nos recuerda el aporte social, cultural y económico que estas realizan:

Las Industrias Culturales son patrimonio histórico y vivo y recurso que proporciona empleo e ingresos, actividad económica que produce retornos tributarios, pero sobre todo son medios para coordinar los deseos, aspiraciones y preocupaciones ciudadanas, de todo aquellos que viene de afuera y queda al margen del espacio público, y así hacerlo asequible para que a partir de allí siga gestándose la creatividad, y transformándose en el combustible más importante de la nueva economía (Yúdice, 2002). 


\section{Referencias Bibliográficas}

Choi, C., Chen, S. y Milton, B. (2004). The Ethics of counterfeiting in the fashion industry: Quality, Credence and profit issues. Journal of Business Ethics. Kluwer Academic Publishers. Volúmen 55, p. 345-354.

Lipovetsky, G. (1987). El Imperio de lo efímero. La moda y su destino en las sociedades modernas. (1ra edición). Editorial Anagrama.

Marino, P. (2010). Diseño de indumentaria de autor en Argentina. Diagnóstico productivo e impacto económico basado en la Encuesta Nacional de Diseño de Indumentaria de Autor 2010. (1 ra edición). Buenos Aires: Ediciones INTI.

Raustiala, K y Sprigman, C. (2006). The Piracy Paradox: Innovation and intellectual property in fashion design. Virginia Law Review. Volumen 92, número 8, p. 1728.

Saulquin, S. (2008). ¿Por qué Argentina? (1 ra edición). TN\&Platex.

The Look of Prada. (2006). In Style Mag. Sep. 2006. Art 213.

Yúdice, G. (2005). Cultura y Desarrollo: Análisis y consecuencias. Seminario "La Cultura como factor de Desarrollo" realizado en la Universidad de Chile el 9 de agosto de 2005.

(2002). Las industrias culturales: más allá de la lógica puramente económica, el aporte social. Ponencia en encuentro de la OEI "Las Culturas de Iberoamérica en el siglo XXI", en Río de Janeiro el 11 y 12 de marzo de 2002.

\section{Recursos Electrónicos}

Barrere, C. (2008). Intellectual Property Rights on Creativity and Heritage: the Case of Fashion Industry. OMI. Universidad de Reims, Francia. Disponible en: www.dime-eu.org/files/active/0/BarrerePAPER.pdf

Blakley, J. (2010). Innovation \& Creativity in the fashion industry. Ponencia en The Noman Lear Center. Mayo 2010. Disponible en: http://www.learcenter.org/html/projects/? $\mathrm{cm}=\mathrm{ccc} /$ fashion García Canclini, N. (2002). Las Industrias Culturales y el desarrollo de los países americanos. Disponible en: http://www.scm.oas.org/idms_public/SPANISH/hist_02/cidi00993s02.doc

INPI (Instituto Nacional de Propiedad Intelectual). Disponible en: www.inpi.gov.ar La propiedad intelectual en la industria de la moda. (mayo y junio de 2005). Revista de la OMPI. Disponible en: http://www.wipo.int/sme/es/documents/wipo_magazine/5_2005.pdf

Scadifi, S. (8/5/2008). Adidas Versus Payless Shoes. Disponible en: www.counterfeitchic.com Sforza, T. (3/4/2006). The fake side of fashion. Disponible en: http://www.cafebabel.co.uk/arti cle/16455/the-fake-side-of-fashion.html.

Tommy Hilfiger Wins Trademark Counterfeiting and Infringement Case. (2003). Disponible en: http://www.allbusiness.com/retail-trade/apparel-accessory-stores-womens-specialty/442457 0-1.html 9/6/2003 
Summary: There exist in our country more of a hundred of clothing designers whose products are quite different from those imposed by global trends. These independent designers, are small entrepreneurs who nourish their creativity and originality with the diverse and wide local culture. This sector undergoes the constant threat of the copy: retailers, foreign brands, foreing designers, among others, observe their proposals eager for new inspirations demanded by consumers. The copy usually collaborates in the legitimización of the creators and innovators. Nevertheless, for these designers, who count on very small structures of little capital work and to invest in diffusion and positioning, the copy can become a weapon of double edge able to destroy all dreams. In this industry a legislation does not exist to protect the creations. The essay analyzes the copy in the fashion industry and the necessity of a copyright legislation for original clothing designs

Key words: brands - copy - copyright - creative process management - fashion design - legislation - local enterprising.

Resumo: Em nosso país existem muitos desenhadores de indumentária que se diferenciam com seus produtos de aqueles impostos pelas tendências globais. Estes desenhadores independiêntes, são pequenos emprendedores que nutrem sua criatividade e originalidade da cultura local, diversa e extensa.

Este setor sofre a constante ameaça da cópia: retailers, marcas, desehadores extrangeiros, entre outros, observam suas propostas ávidos de novas inspirações demandadas pelos consumidores. A cópia colabora na legitimação dos criadores e inovadores. Mas para estes desenhadores, que contam com estruturas de trabalho muito pequenas e pouco capital para inverter em difusão e posicionamento, a cópia pode se converter numa arma perigosa capaz de chegar a destruir todos seus sonhos.

Nesta indústria não existe uma legislação que proteja as criações. O ensaio analisa a cópia na indústria da moda e a necessidade de direitos de propriedade intelectual para as prendas originais de indumentaria.

Palavras chave: cópia - design de indumentária - direitos de propriedade intelectual - emprendimentos nacionais - gestão do processo criativo - legislação - marcas. 